\title{
A century of fish biomass decline in the ocean
}

\author{
Villy Christensen ${ }^{1, *}$, Marta Coll ${ }^{2,3}$, Chiara Piroddi $^{4}$, Jeroen Steenbeek ${ }^{3}$, \\ Joe Buszowski ${ }^{3}$, Daniel Pauly ${ }^{1}$ \\ ${ }^{1}$ Fisheries Centre, University of British Columbia, 2202 Main Mall, Vancouver, BC V6T 1Z4, Canada \\ ${ }^{2}$ Institut de Recherche pour le Développement, UMR EME 212, \\ Centre de Recherche Halieutique Méditerranéenne et Tropicale, Avenue Jean Monnet, BP 171, 34203 Sète Cedex, France, \\ and Institute of Marine Science, ICM-CSIC, Passeig Marótim de la Barceloneta, 37-49, Barcelona 08003, Spain \\ ${ }^{3}$ Ecopath International Initiative Research Association, Barcelona, Spain \\ ${ }^{4}$ European Commission - DG JRC, Institute for Environment and Sustainability, Water Resources Unit, Via E. Fermi, \\ 2749 - TP 272, 21027 Ispra, VA, Italy
}

\begin{abstract}
We performed a global assessment of how fish biomass has changed over the last $100 \mathrm{yr}$, applying a previously developed methodology using ecological modeling. Our assessment built on more than 200 food web models representing marine ecosystems throughout the world covering the period from 1880 to 2007. All models were constructed based on the same approach, and have been previously documented. We spatially and temporally distributed fish biomasses delivered by these models based on fish habitat preferences, ecology, and feeding conditions. From these distributions, we extracted over 68000 estimates of biomass (for predatory and prey fishes separately, including trophic level of 3.5 or higher, and trophic level between 2.0 and 3.0, respectively), and predicted spatial-temporal trends in fish biomass using multiple regression. Our results predicted that the biomass of predatory fish in the world oceans has declined by twothirds over the last $100 \mathrm{yr}$. This decline is accelerating, with $54 \%$ occurring in the last $40 \mathrm{yr}$. Results also showed that the biomass of prey fish has increased over the last $100 \mathrm{yr}$, likely as a consequence of predation release. These findings allowed us to predict that there will be fish in the future ocean, but the composition of fish assemblages will be very different from current ones, with small prey fish dominating. Our results show that the trophic structure of marine ecosystems has changed at a global scale, in a manner consistent with fishing down marine food webs.
\end{abstract}

KEY WORDS: Fish biomass · Global distribution · Trends · Ecosystem models · Fishing down marine food webs

Resale or republication not permitted without written consent of the publisher

\section{INTRODUCTION}

Opinions regarding the state and future of marine resources differ. Many fear that we are losing ground in this last frontier on the globe, and that our impact is so devastating that all fish stocks will be collapsed by 2048 (Worm et al. 2006), while alternative interpretations of data conclude that conditions are improving and we are seeing improvements in fish populations (Worm et al. 2009). Such conflicting findings have, while creating headlines, sparked a heated discussion within the scientific community and have created confusion for fisheries managers and the general public.

In this study, we evaluate how the abundance of fish has changed in the world ocean over the last 100 yr. Building on a methodology that combines food web modeling, statistical analysis and geographic information systems, as well as physical and ecological global spatial datasets, our study is the first to evaluate trends in global fish biomass based on stratification of the world's oceans using food web models.

We used 200 detailed descriptions of ecosystems in the form of ecosystem food web models to provide 
snapshots of how much life was in the ocean at given points in time and space. We then evaluated how the conditions at each point related to environmental parameters, based on which we developed a regression model to predict biomass trend over time. Finally, we used global environmental databases to predict the spatial distribution of fish biomass. For the study, we used an established methodology previously applied to the North Atlantic, Southeast Asia, and West Africa (Christensen et al. 2003a,b, 2004).

This study allowed us to predict the biomass trends for higher trophic level fish, i.e. the larger predatory fish or 'table fish', as well as for the lower trophic level prey fish, such as small pelagic fish (e.g. sardines, anchovies, capelins), which are used mainly for fishmeal and oil (Pikitch et al. 2013). Local and regional studies have reported important declines of large predators in the ocean (Christensen et al. 2003b), including large finfish and sharks (Baum et al. 2003, Myers \& Worm 2003). In parallel, some studies have indicated that the abundance of forage fishes and invertebrates may have increased due to cascading effects caused by decreasing predator abundance as a result of human exploitation (Carscadden et al. 2001, Worm \& Myers 2003, Myers et al. 2007, Coll et al. 2013).

Given the recent controversy over whether 'fishing down the food web' is a phenomenon actually occurring in nature (Pauly et al. 1998) or a sampling artifact (Branch et al. 2010) with no or little relation to the underlying ecosystem structure, our study adds to the discussion by specifically evaluating how the biomass of high trophic level species has changed relative to the biomass of low trophic level species.

\section{MATERIALS AND METHODS}

\section{Ecosystem models}

We built a database with 230 ecosystem models, all of which were based on the Ecopath with Ecosim (EwE) approach and software (Christensen \& Pauly 1992, Christensen \& Walters 2004), currently the most widely used ecosystem modeling approach in the marine environment (Coll et al. 2008a, Colléter et al. 2013, Heymans et al. 2014). EwE integrates a large body of information from the ecosystem in a coherent description of aquatic food webs, placing human activities within an ecosystem context, and accounts for environmental changes (Christensen \& Walters 2004). For detailed information about the EwE approach, its main advantages and limitations, see the literature (e.g. Christensen \& Walters 2004, Plagányi 2007), and www.ecopath.org.

Each of these EwE models was constructed by ecosystem modelers (i.e. fisheries scientists, ecologists or marine biologists) using local and regional datasets, usually with the aim of providing a snapshot of an ecosystem in a given year, and which had been previously published and well documented in the scientific literature (see the Supplement at www.int-res. com/articles/suppl/m512p155_supp.pdf). These models jointly cover $44 \%$ of the world's ocean surface (Fig. 1), representing the years between 1880 and 2007 (the number of models in 3 time periods within those years are indicated in Table 1).

For the analysis, we first used the snapshot Ecopath models. We evaluated and quality-controlled the available Ecopath models, eliminating 30 of the candidate models from our analysis. As criteria for inclusion, models must have been well documented in the literature, included biomass information for different fish groups as inputs, and the modeled food webs must have accounted for all living components in traceable detail. For example, we eliminated models that only specified fish groups as 'fish'. For each of the 200 remaining ecosystem models, we evaluated which of its functional groups belonged to the wider category of 'exploitable fish species'. We excluded mesopelagic species, which mainly occur in the deep, open ocean and which cannot be exploited economically with existing technology (Valinassab et al. 2007). We also excluded juvenile fish, which cannot form the basis of sustainable fisheries (Libralato et al. 2008).

We performed the analysis separately for fish with a trophic level of 3.5 or higher, and for fish with a trophic level between 2.0 and 3.0. The higher-trophic level group includes predatory fish and represents the larger 'table fish' that tend to be used directly for human consumption. The lower trophic level groups tend to be 'forage fish', a major prey for the table fish and other marine predators (Cury et al. 2011, Pikitch et al. 2012). Humans tend to use forage fish mainly for fishmeal and oil (Alder et al. 2008, Pikitch et al. 2012). We also excluded invertebrate species from this analysis since there is less information about them, and ecosystem models tend to lack information on these organisms (but see Pauly et al. 2009, Coll et al. 2013).

There were approximately 3000 types (unique names) of functional groups in the ecosystem models. Each functional group represents individual species, life stages of species, or a collection of similar species (for instance, 'small pelagic fishes'). We assigned each of the functional groups to depth categories, based on information from FishBase (Froese \& Pauly 


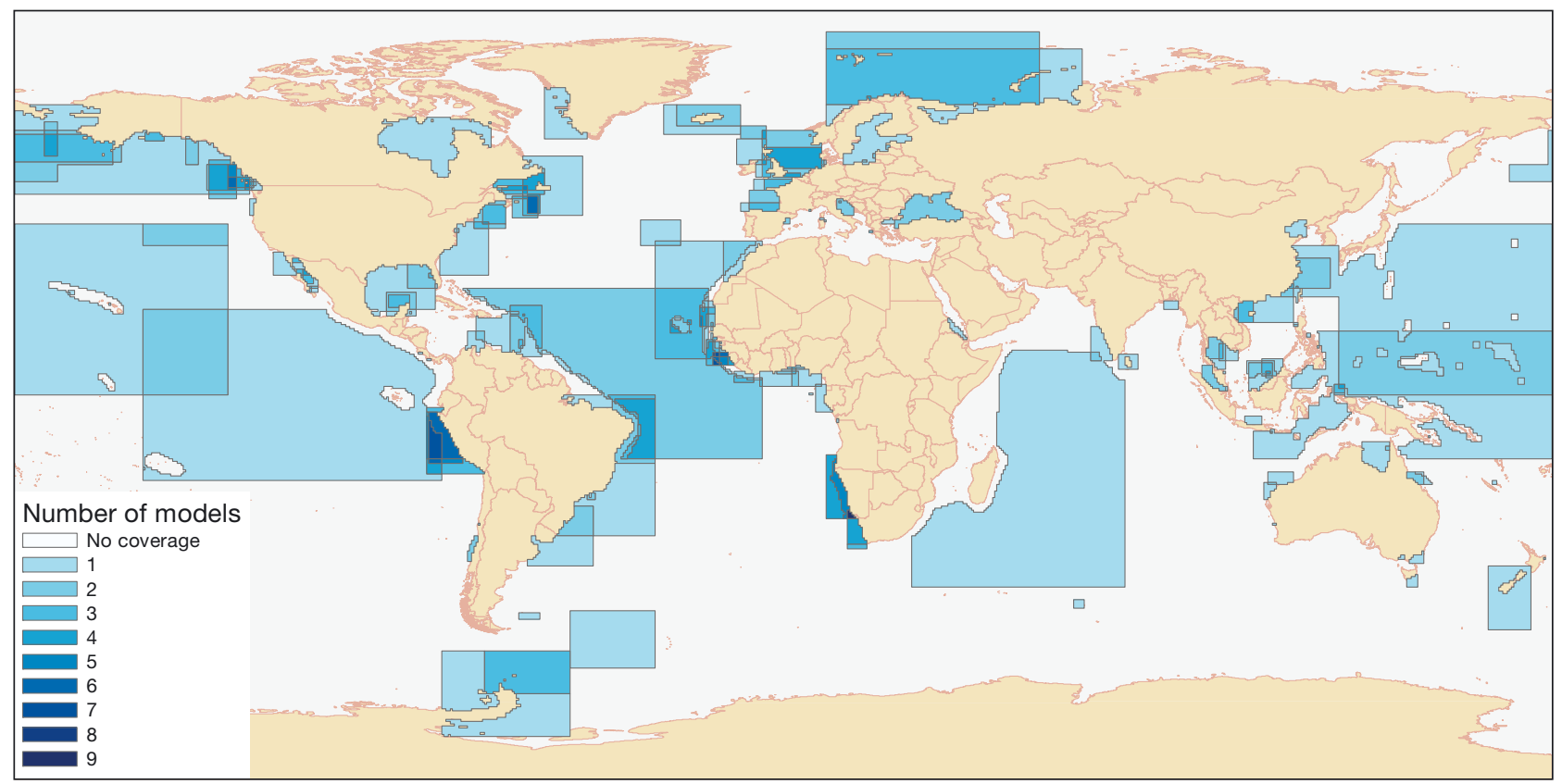

Fig. 1. Spatial distribution of the ecosystem models used in this study, illustrating the wide global coverage. Color density is indicative of the number of models at each location

2013), SeaLifeBase (Palomares \& Pauly 2013), Aquamaps (Kaschner et al. 2013), other online searches, and general knowledge of the species involved. The depth stratifications we used were $<10,10-49$, 50-99, 100-199, 200-499, 500-999, 1000-1999, and $>2000 \mathrm{~m}$, and did not include habitat type. Each functional group could be assigned to any number of depth strata, with most pelagic species (for example) being assigned to all strata.

Secondly, we used the spatial-dynamic Ecospace module of EwE (Walters et al. 1999) to spatially distribute the functional groups within each Ecopath ecosystem model based on standardized habitat distributions as described above, using the depth stratification categories. We used a time-spatial dynamic simulation of 30 yr per Ecopath model. Default values of the vulnerability parameter were used. In addition to depth stratification, the models used relative primary production as input, derived from SeaWiFS satellite data. The ecosystem models were then dis-

Table 1. Number of ecosystem models by time period that were included in the analyses

\begin{tabular}{|lc|}
\hline Period & Number \\
\hline $1880-1969$ & 35 \\
$1970-1989$ & 97 \\
$1990-2010$ & 108 \\
\hline
\end{tabular}

tributed spatially to a global half-degree grid, based on information in the model descriptions. The distribution by the available ecosystem models (Fig. 1) highlights the wide coverage of the global ocean. It is also important to note that for many locations, several models were available from different periods, which was important for obtaining estimates of how fish abundance has changed over time (Fig. 1 and the Supplement).

From the spatial models, we extracted 68039 predictions of fish biomass by cell and year, which subsequently were used as a basis for multiple regression analyses.

\section{Multiple regression analyses}

Regression analyses to model the biomass of predatory and forage fish were done using the open source R-package. We considered the following predictor variables: (1) year, (2) latitude, (3) bottom depth (from www.ngdc.noaa.gov/mgg/fliers/01mgg 04.html), (4) distance from coast (modified from www.ngdc.noaa.gov/mgg/fliers/01mgg04.html), (5) density of seamounts (Christensen et al. 2011, www. seaaroundus.org), (6) absolute primary production (http://oceancolor.gsfc.nasa.gov/SeaWiFS/), (7) average of surface and bottom temperature (from www. noaa.gov/), (8) zooplankton biomass (Bogorov et al. 
1968, FAO 1981, www.seaaroundus.org, Christensen et al. 2011), (9) macrobenthos biomass (Christensen et al. 2011, www.seaaroundus.org), (10) mesopelagic fish biomass (Gjøsaeter \& Kawaguchi 1980, Lam \& Pauly 2005, www.seaaroundus.org, Christensen et al. 2011), (11) upwelling index (from www.pfeg.noaa. gov/products/las/docs/global_upwell.html), and (12) FAO statistical areas (from www.seaaroundus.org).

Our methodology builds directly on 3 previous studies of trends in fish biomass in the North Atlantic, Southeast Asia, and off West Africa (Christensen et al. 2003a,b, 2004). A detailed flow diagram of the procedure is provided by Christensen et al. (2003b). As in previous applications of this methodology, the environmental parameters were treated as static in the analysis, while in reality they show considerable inter-annual variability. However, we do not have access to a time series of all the environmental data used in this analysis covering the time period of interest (as such data do not exist).

We used additive and variance stabilizing transformations as implemented in the AVAS (additivity and variance stabilization for regression) module of the acepack R-library to check for linearity between the predictive variables and the dependent variable (i.e. the biomass of potentially exploitable fish with trophic level of 3.5 or higher or trophic level between 2.0 and 3.0).

After model exploratory selection using the $\mathrm{lm}$ module of R (R-library gamair) to assess the contribution of each independent variable to the model, we excluded the following independent variables: latitude, because of its covariance with temperature and FAO area; depth, because of its covariance with distance from coast; density of seamounts, because our sample of the ecosystem model collection did not have a good coverage of seamount models; zooplankton biomass, because of its covariance with primary production; macrobenthos biomass, because of its covariance with depth; and mesopelagic fish biomass, because it did not significantly correlate with the independent variable.

We included 19 marine FAO statistical areas as potential factorial variables, but ignored 4 of these areas for which we had less than 5 models. We thus did not use FAO areas 51, 58, 81, and 88 as factorial variables in the regressions; however, models from these areas were used for the predictions, i.e. they were treated as if the FAO areas in which they occur were not specified.

The AVAS transformations (Fig. 2) indicated that the dependent variable (biomass) should be logtransformed, along with 2 of the predictor variables (primary production and distance from the coast). The temperature transformation had a peculiar shape indicating divergence from linearity, which is likely due to the very limited observations available for waters where the average of bottom and surface temperature exceeded $20^{\circ} \mathrm{C}$.

After transformation of the variables, we used the biomass results from the 200 ecosystem models to evaluate the time trend in fish biomass over the last 100 yr. We also estimated how fish biomass had changed during 3 time periods: 1910 to 1970,1970 to 1990 , and 1990 to 2010 (see Table 3). We chose these splits since the North Atlantic fish catches peaked around 1970, and this was the period when fisheries expansion gained momentum throughout the world (Coll et al. 2008b, Swartz et al. 2010). By 1990, this expansion had reached a new level and fisheries resource depletion had become a global phenomenon.

The multiple linear regressions had the following form:

$$
\begin{gathered}
\log _{\mathrm{e}}(\text { biomass })=a+b_{1} \times \text { year }+b_{2} \times \log _{\mathrm{e}}(\text { distance })+ \\
b_{3} \times \log _{\mathrm{e}}(\text { primary production })+b_{4} \times \text { temperature }+ \\
b_{5} \times \text { upwelling index }+b_{i} \times \text { factor }(\text { FAO })
\end{gathered}
$$

where $a$ is the regression intercept, $b_{1}$ to $b_{5}$ are the regression coefficients, and $b_{i}$ is a coefficient for each of the categorical FAO variables. In the regressions, we weighted each of the 68039 estimates of fish biomass by time and space with $1 / \log _{\mathrm{e}}$ (number of spatial units), i.e. with the inverse of the log of the number of half-degree cells covered by each of the ecosystem models. This was done to limit the influence of models covering very large spatial areas (Christensen et al. 2003a,b, 2004). Since the spatial resolution of the ecosystem models was a half-degree latitude by half-degree longitude, and because each cell was sampled only once for each model, spatial autocorrelation and pseudoreplication were avoided (Legendre 1993, Guisan \& Zimmermann 2000).

Since results from regressions depend on what ecosystem models are included as data inputs, we evaluated the robustness of the regression by jackknifing (leaving out one ecosystem model at a time), and found that this had no noteworthy effects on the results, as previously found in regional studies (Christensen et al. 2003a,b, 2004). We further evaluated uncertainty by resampling: we randomly selected $30 \%$ of the 68039 estimates of fish biomass 1000 times, and evaluated predicted biomass trends from the subsampling.

The regression coefficients and test statistics were analyzed from the regression analysis. 


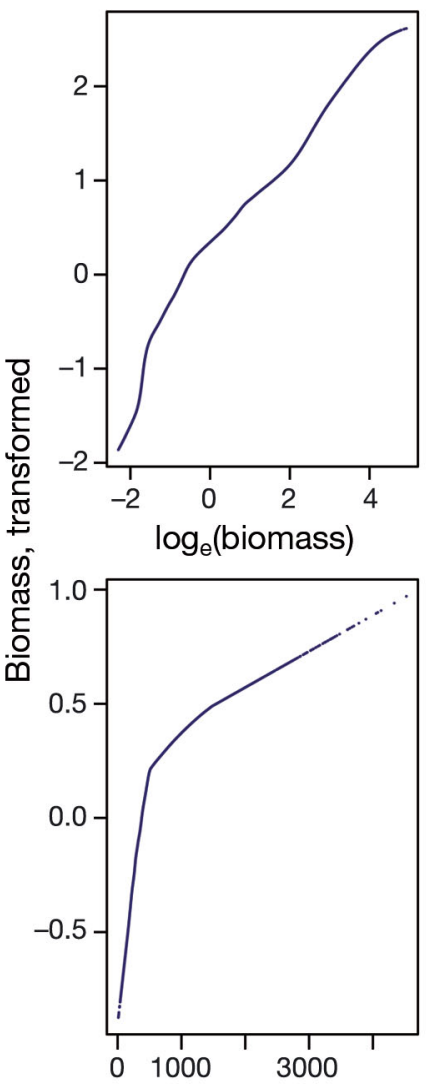

Prim. prod.
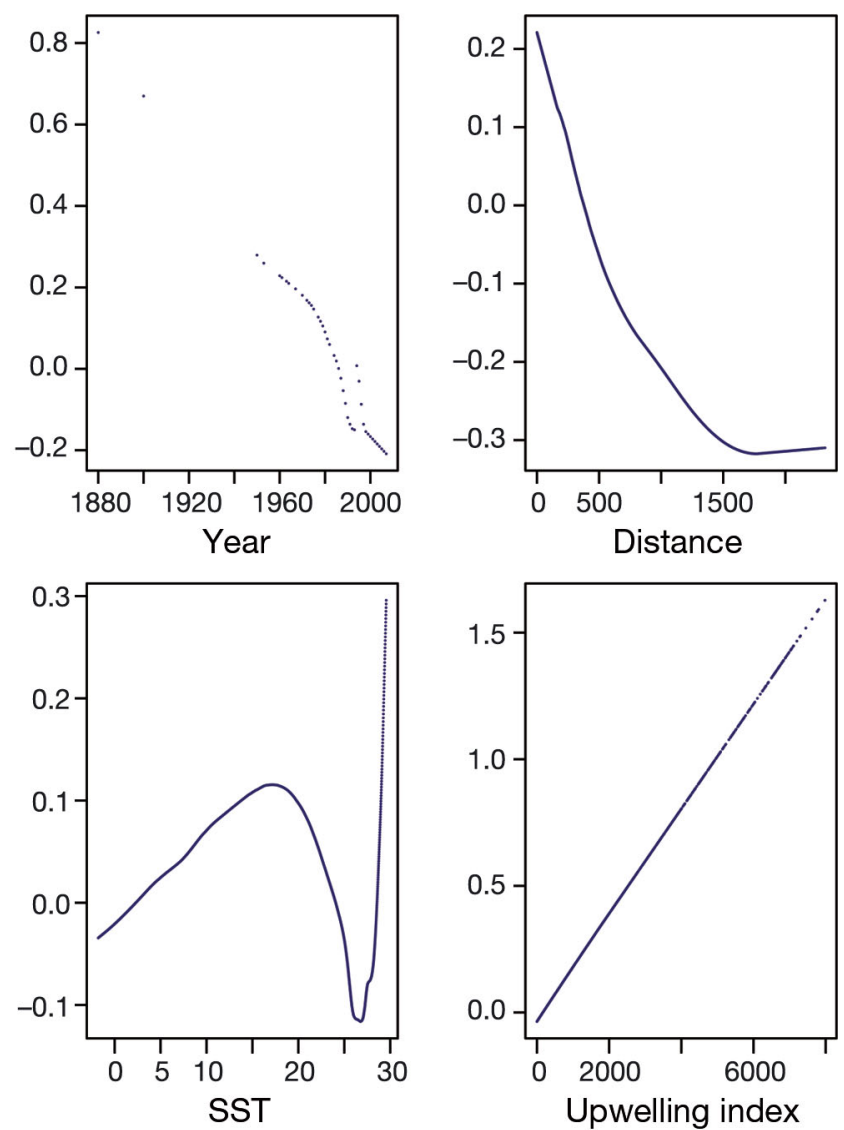

Fig. 2. Additivity and variance stabilization for regression (AVAS) transformation of independent variables included in the regression analysis. The analysis indicates that $\log _{\mathrm{e}}$-transformation should be used for biomass, primary production, and distance from coast

Finally, we used the regression analyses (based on the total data set and on resampled sets), jointly with a global database with the predictor parameters (with halfdegree resolution) to estimate global, spatial biomass distributions of fish from 1950 and from 2010.

\section{RESULTS}

\section{Biomass of predatory fishes}

Our evaluations indicated that the biomass of predatory fish has declined significantly over the last 100 yr. For the 200 models covering the entire time period from 1880 to 2010 , the multiple regression coefficient, $\mathrm{r}^{2}=0.70$, indicating that the regression explained $70 \%$ of the variation in the data set, which is highly significant (Table 2). The predictor variables were all highly significant, apart from the factorial variable for FAO areas 18 and 31 (representing the Amerasian Arctic and the Caribbean, respectively).
Table 2. Parameter coefficients and associated test statistics for multiple linear regressions to predict the global marine biomass of predatory fishes (multiple $\mathrm{r}^{2}=0.70$ ). The $t$-value is the ratio between an estimate and its standard error, and $\operatorname{Pr}(>|t|)$ indicates the probability of obtaining a larger $t$-value. The smaller this probability is, the higher the significance of this parameter. ns: not significant; ${ }^{*} \mathrm{p}<0.05,{ }^{* * *} \mathrm{p}<0.001$

\begin{tabular}{|lrrcc|}
\hline & Estimate & $t$-value & $\operatorname{Pr}(>|t|)$ & Significance \\
\hline Intercept & 24.2500 & 54.8 & $2.00 \mathrm{E}-16$ & ${ }^{* * *}$ \\
Year & -0.0151 & -69.7 & $2.00 \mathrm{E}-16$ & ${ }^{* * *}$ \\
log $_{\mathrm{e}}$ (distance) & -0.1008 & -28.0 & $2.00 \mathrm{E}-16$ & ${ }^{* * *}$ \\
loge (prim. prod.) $^{*}$ & 1.1040 & 142.8 & $2.00 \mathrm{E}-16$ & ${ }^{* * *}$ \\
Temperature & -0.0608 & -69.6 & $2.00 \mathrm{E}-16$ & ${ }^{* * *}$ \\
Upwelling index & 0.0002 & 42.4 & $2.00 \mathrm{E}-16$ & ${ }^{* * *}$ \\
FAO 18 & 0.0978 & 2.0 & 0.0407 & ${ }^{*}$ \\
FAO 21 & 0.6361 & 19.9 & $2.00 \mathrm{E}-16$ & ${ }^{* * *}$ \\
FAO 27 & 0.7966 & 28.4 & $2.00 \mathrm{E}-16$ & ${ }^{* * *}$ \\
FAO 31 & 0.0605 & 1.7 & 0.0907 & $\mathrm{~ns}$ \\
FAO 34 & -0.1952 & -6.0 & $2.33 \mathrm{E}-09$ & ${ }^{* * *}$ \\
FAO 37 & -0.4279 & -8.4 & $2.00 \mathrm{E}-16$ & ${ }^{* * *}$ \\
FAO 41 & 1.0460 & 31.0 & $2.00 \mathrm{E}-16$ & ${ }^{* * *}$ \\
FAO 47 & 0.6778 & 18.2 & $2.00 \mathrm{E}-16$ & ${ }^{* * *}$ \\
FAO 48 & 1.1660 & 32.8 & $2.00 \mathrm{E}-16$ & ${ }^{* * *}$ \\
FAO 57 & 1.1920 & 26.1 & $2.00 \mathrm{E}-16$ & ${ }^{* * *}$ \\
FAO 61 & 1.1250 & 35.6 & $2.00 \mathrm{E}-16$ & ${ }^{* * *}$ \\
FAO 67 & 1.5880 & 51.4 & $2.00 \mathrm{E}-16$ & ${ }^{* * *}$ \\
FAO 71 & 1.2270 & 36.1 & $2.00 \mathrm{E}-16$ & ${ }^{* * *}$ \\
FAO 77 & 0.4832 & 14.9 & $2.00 \mathrm{E}-16$ & ${ }^{* * *}$ \\
FAO 87 & 0.3341 & 9.7 & $2.00 \mathrm{E}-16$ & ${ }^{* * *}$ \\
& & & & \\
\hline
\end{tabular}




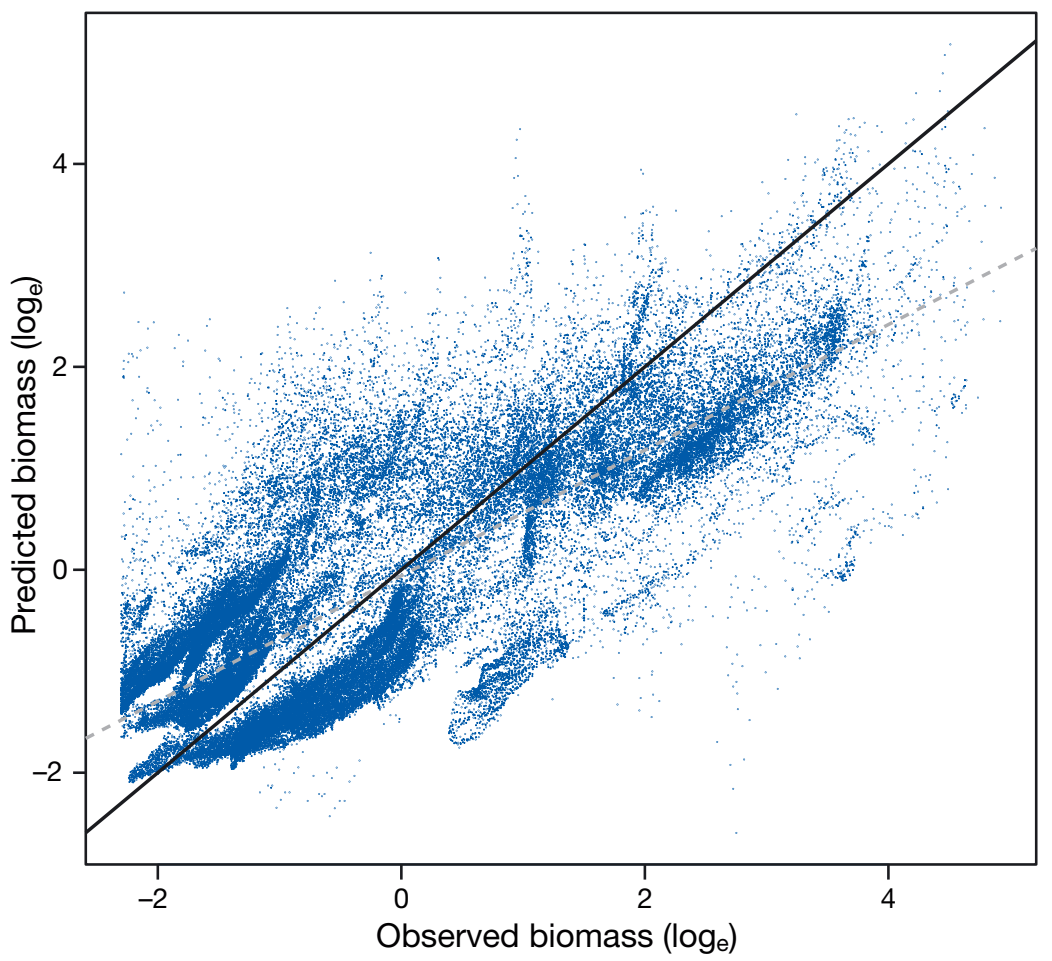

Fig. 3. Predicted versus observed biomass $\left(\log _{\mathrm{e}}\right.$-scales, $\mathrm{t} \mathrm{km} \mathrm{km}^{-2}$ ) for higher trophic level fish in the world ocean. Solid line indicates the 1:1 line; dotted line is the observed average trend. The predicted variables underestimate the observed variability

Our results showed that the signs of the predictor variable coefficients were negative for biomass, distance, and temperature, and positive for primary production and the upwelling index (Table 2). Notably, the regression indicated that we have lost $1.5 \%$ of the biomass of higher trophic level fish annually since 1880, and that biomass declines 5 to $6 \%$ for every degree of higher water temperature.

If we examine the relationship between observed and predicted values based on the regression in Table 2, we see that the regression overestimated abundance at low biomass and underestimates at high biomass (Fig. 3). This indicates that the regression was conservative, i.e. it did not overestimate the trend in biomass. It also means that the residuals (predicted less observed values) were negative at low biomasses and positive at high biomasses. Such a structure in the residuals suggests that there are 'hidden' predictors, i.e. variables that have not been included in the multiple regressions. This should not come as a surprise given that we seek to predict the biomass based on a limited number of variables: year, distance from coast, primary production, temperature, upwelling, and FAO area. While these parameters do lead to a skewed residuals overall, only the upwelling index shows indication of a divergence from linearity (Fig. 4). These results suggest, overall, that our predictor variables are suitable for use in the regressions.

Using a resampling methodology, we randomly drew $30 \%$ of the estimates of biomass over space and time and performed a multiple regression with each subsample for the 3 time periods analyzed. Based on this analysis, we obtained a distribution for each predictor variable (Fig. 5). We then used each of the resampled regressions and the database of environmental parameters to predict global biomasses. From this, we estimated that the biomass of predatory fishes has declined by around 75\% during the 100 yr from 1910 to 2010.

Dividing the models into 3 time periods to obtain higher temporal resolution (Table 1), and with the splits made in 1970 and 1990, we obtained multiple linear regressions similar to that reported above for the entire time period (Table 3). Again, the predictor variables were highly significant $\left(\mathrm{p}<10^{-16}\right)$ and the regressions explain 66 to $91 \%$ of the variability in the biomass data.

Evaluating the time trends based on resampling the 3 regressions 1000 times based on randomly selecting $30 \%$ of the biomass estimates, our results showed that the biomass of predatory fishes has declined by two-thirds ( $66.4 \%$ with $95 \%$ confidence intervals ranging from $60.2-71.2 \%$ ) over the last $100 \mathrm{yr}$ (Fig. 6). This decline is estimated to have been slow during the first period $\left(10.8 \%\right.$ or $0.2 \% \mathrm{yr}^{-1}$ up to $1970)$, then severe during the second period $(41.6 \%$ or $4.0 \% \mathrm{yr}^{-1}$ during 1970 to 1990 ), and slower during the third period (14.0\% or $2.9 \% \mathrm{yr}^{-1}$ since 1990$)$.

\section{Biomass of lower trophic level fish}

We repeated the same procedure as described above to predict the biomass of lower trophic level fish (with trophic level between 2.0 and 3.0). Results from the multiple linear regressions for the entire time period (Table 4) showed a positive and significant regression coefficient for year (0.0085). This indicated that the biomass of prey fish had been increasing over time by $0.85 \% \mathrm{yr}^{-1}$. Over a $100 \mathrm{yr}$ time 

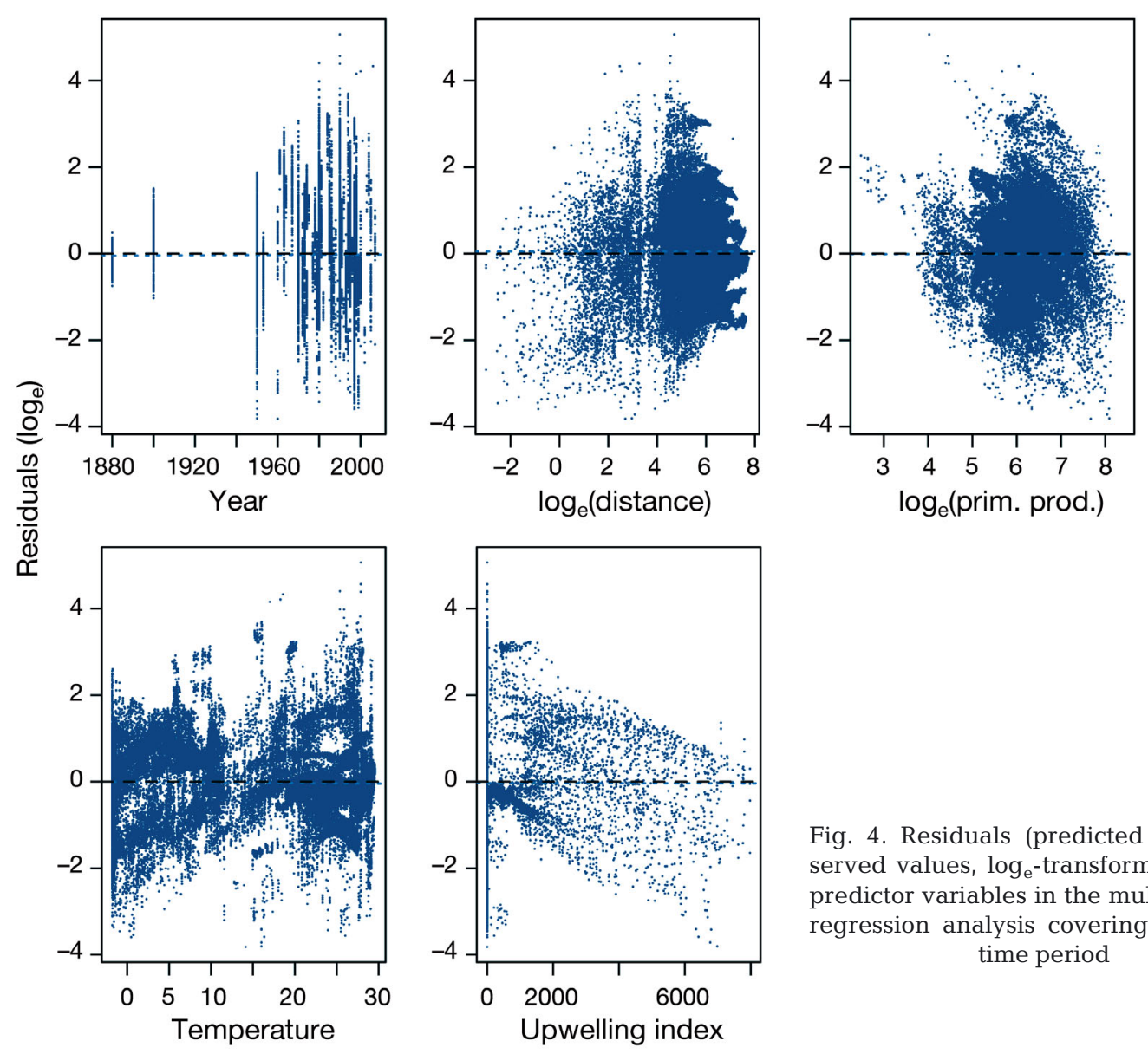

Fig. 4. Residuals (predicted minus observed values, $\log _{\mathrm{e}}$-transformed) for the predictor variables in the multiple linear regression analysis covering the entire time period
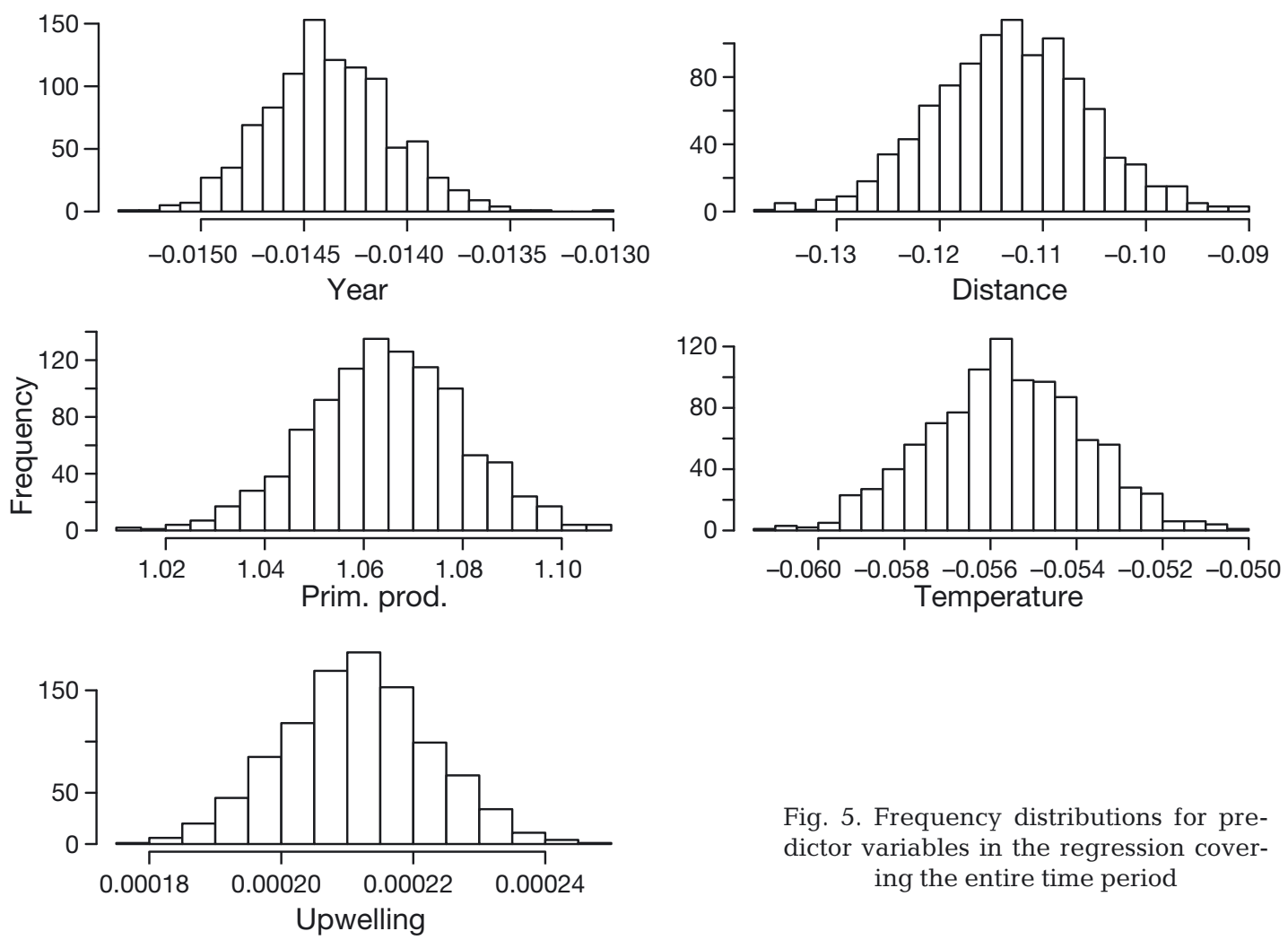

Fig. 5. Frequency distributions for predictor variables in the regression covering the entire time period 
Table 3. Regression coefficients for predictor variables for the 3 time periods considered, used to estimate the $\log _{\mathrm{e}}$ (biomass) of predatory fishes (trophic level >3.5). Coefficients for FAO areas are not listed for clarity

\begin{tabular}{|lrrr|}
\hline & $1880-1969$ & $1970-1989$ & $1990-2010$ \\
\hline Intercept & 0.5489 & 76.5400 & 51.5800 \\
Year & -0.0021 & -0.0411 & -0.0293 \\
$\log _{\mathrm{e}}$ (distance) & -0.1054 & -0.1183 & -0.0700 \\
loge $_{\mathrm{e}}$ (prim. prod.) & 1.1000 & 1.0530 & 1.1950 \\
Temperature & -0.1917 & -0.1008 & -0.0335 \\
Upwelling index & 0.0001 & 0.0001 & 0.0004 \\
$\mathrm{r}^{2}$ & 0.9117 & 0.6721 & 0.6562 \\
\hline
\end{tabular}

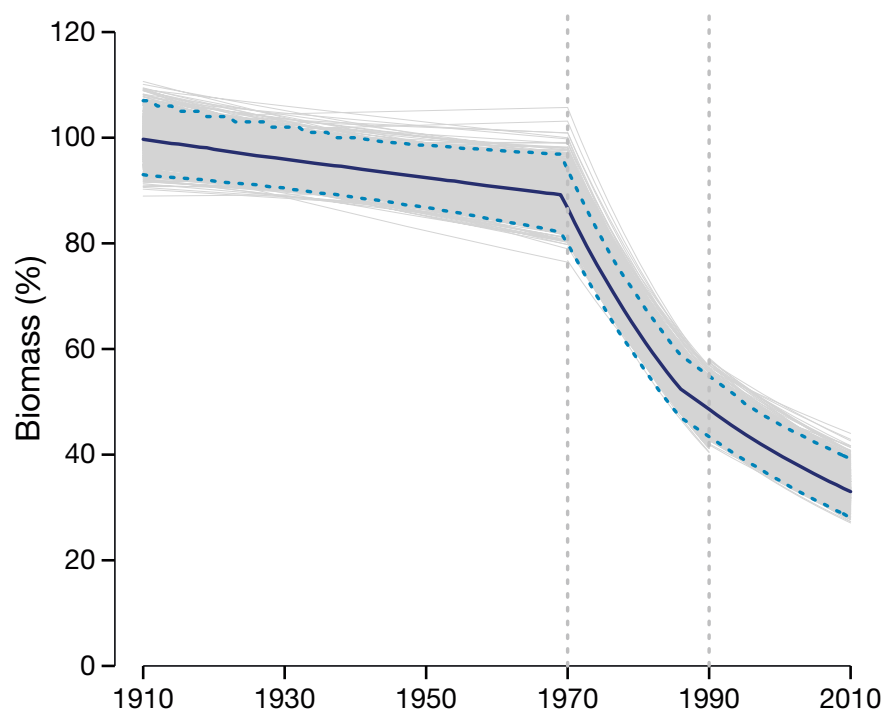

Fig. 6. Global biomass trends for predatory fish during 1910 to 2010 as predicted based on 200 ecosystem models and 1000 times random resampling of $30 \%$ of data points. The lines indicate median values and $95 \%$ confidence intervals

period, this corresponds to a $130 \%$ increase, suggesting that there are now more than twice as many prey fish in the global ocean as there were a century ago.

\section{Spatial biomass distributions}

Results of the global spatial biomass distributions of predatory fish highlighted notable changes with time (Fig. 7), especially evident in the Northern Hemisphere and main upwelling systems. Predicted predatory fish biomass during the 1950s showed higher values of biomass in the Northern Hemisphere and upwelling systems (Fig. 7a). Results from 2010 showed large changes in these areas, with a general decrease of biomass spatially notable in the north and generally in coastal areas and shelf ecosystems (Fig. 7b).
Table 4. Regression coefficients for predictor variables for prey fish (trophic level between 2.0 and 3.0) covering the entire time period. Coefficients for FAO areas are not listed for clarity

\begin{tabular}{|lrr|}
\hline & Estimate & \multicolumn{1}{c|}{$t$} \\
\hline Intercept & -14.5200 & 54.8 \\
Year & 0.0085 & -69.7 \\
$\log _{\mathrm{e}}$ (distance) & -0.5958 & -28.0 \\
$\log _{\mathrm{e}}$ (prim. prod.) & 0.7790 & 142.8 \\
Temperature & -0.1269 & -69.6 \\
Upwelling index & 0.0001 & 42.4 \\
$\mathrm{r}^{2}$ & 0.5572 & \\
\hline
\end{tabular}

\section{DISCUSSION}

Through this study, we further refined a methodology we originally introduced to describe how the biomass of predatory fish has changed in the North Atlantic, West Africa, and Southeast Asia (Christensen et al. 2003a,b, 2004). Extending this methodology, the aim was to provide a first global estimate for how fish biomass has changed over the last century, drawing on a vast amount of information made available through data-rich ecosystem models (Christensen \& Pauly 1992, Christensen \& Walters 2004) to add to the general discussion of the status of marine resources worldwide.

Our results show major declines in the biomass of predatory fish (i.e. of the larger fish that humans tend to eat), amounting to a decline of two-thirds over the last century, with $55 \%$ of the decline occurring in the last $40 \mathrm{yr}$. Indications are that the decline was sharpest during the period between 1970 and 1990, and has since leveled off somewhat. This does not mean, however, that conditions have started to improve globally; we found no indications of increase in biomass of predatory fish. There may be regional improvements (Worm et al. 2009, Lotze et al. 2011), however, this is not evident yet at a global scale.

These results could indicate that we have been fishing past the maximum sustainable yield (MSY) level (Hilborn \& Walters 1992). Productivity for higher trophic level fish populations (e.g. tuna) may indeed be maximized when populations are reduced to between one-third and half of their original biomass, but our study shows that this reduction is an overall average. The implication is that some higher trophic level species (notably the larger species) may likely be reduced even more, while smaller species will have declined less, yet the overall average indicates a large reduction. This is in accordance with one of the most thorough studies of top predator abundance 


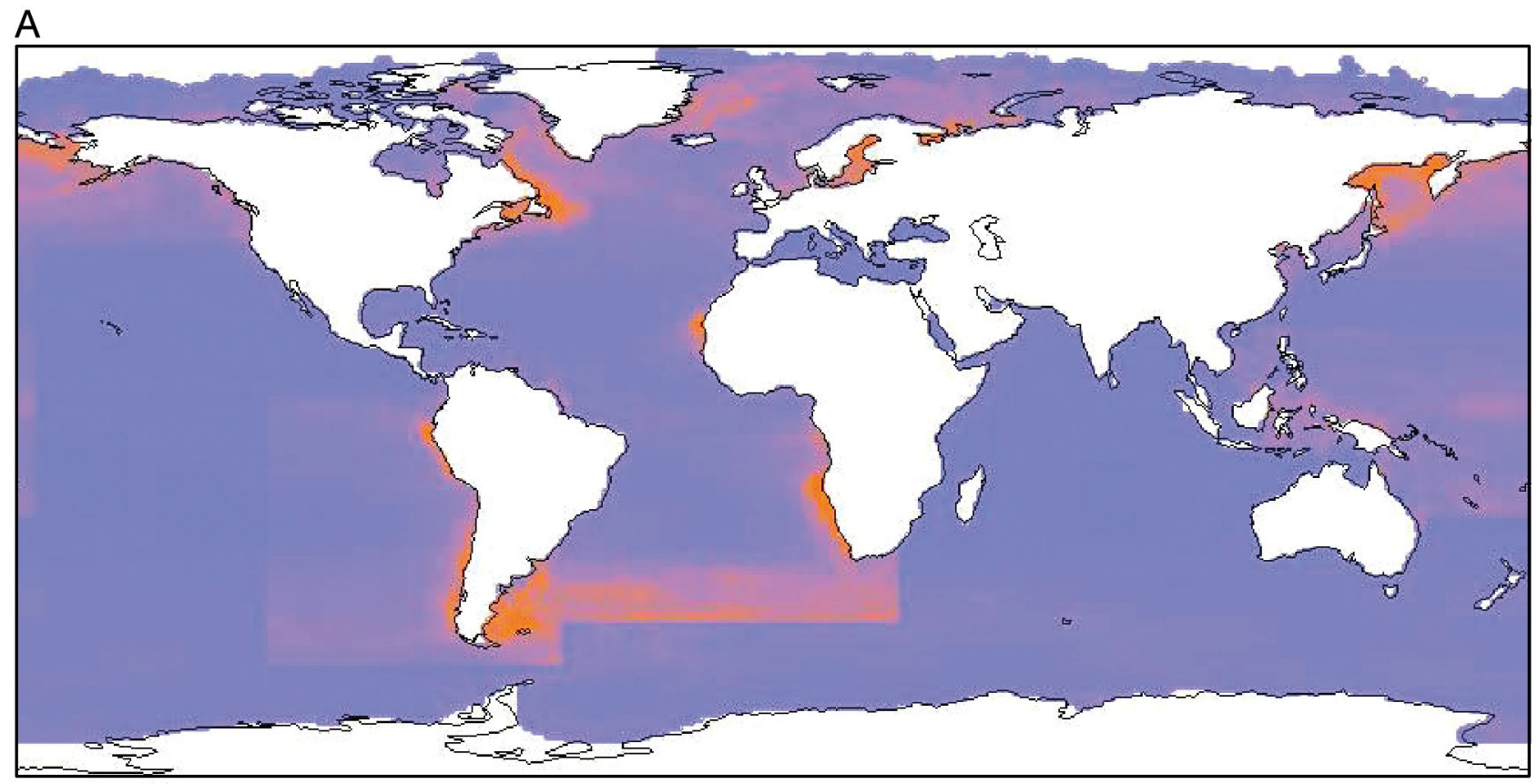

B

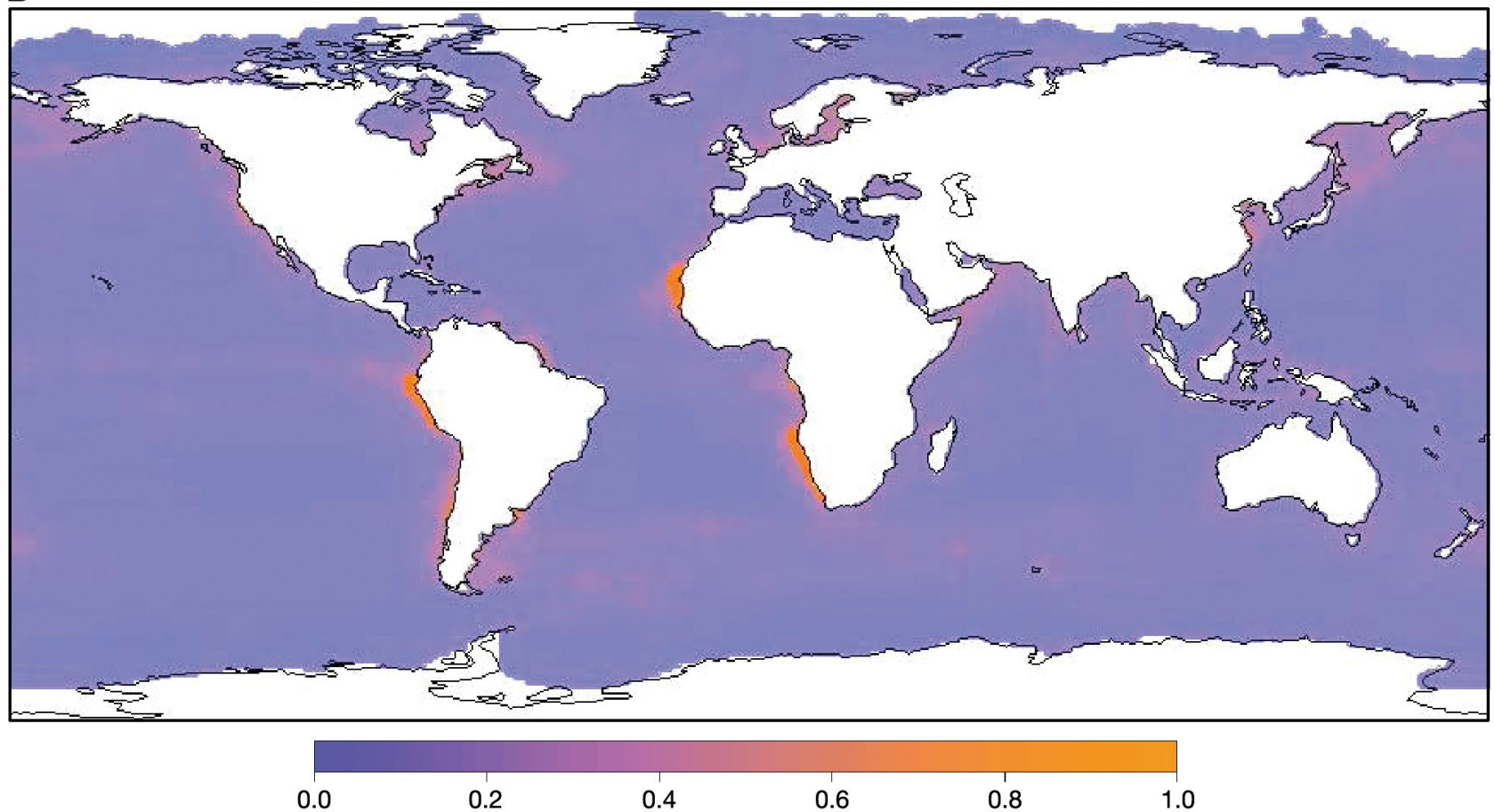

Fig. 7. Global spatial biomass distribution of predatory fish for (a) 1950 and (b) 2010

(Sibert et al. 2006). For the Pacific Ocean, it was estimated that the largest pelagic fish $(>175 \mathrm{~cm}$ fork length) had decreased to $17 \%$ of the unexploited biomass, whereas the decline was much lower for the smaller species. We also note that it indeed is impossible to fish all species at the MSY level; doing so may have severe impacts on the trophic structure of the ecosystem (Walters et al. 2005).
Our results are also in line with previous regional studies using the same methodology. For example, a decline of high trophic level fishes by two-thirds during a $50 \mathrm{yr}$ period and by a factor of 9 between 1880 and 1998 was documented to have occurred in the North Atlantic (Christensen et al. 2003b). In West Africa, previous analysis showed fish biomass (excluding low trophic level and small fishes) has de- 
clined over a 40 yr period from 1960 to 2000 by a factor of 13 (Christensen et al. 2004). In Southeast Asia, the abundance of fish with trophic levels of 3.0 or higher in 2000 was less than half the value in 1960 (Christensen et al. 2003a). It is interesting to note that this study reports similar, but somewhat lower, estimates of predatory fish biomass declines than previous studies. It may be possible that by focusing exclusively on high trophic-level fish (and not just on target species), the present study is less biased towards detection of large ( 90\%) declines (Myers \& Worm 2003, Ferretti et al. 2010).

The decline in predatory fish biomass is closely linked to increased fishing effort. Anticamara et al. (2011) found that global fishing capacity (measured in potential kilowatt days) increased 54\% from 1950 to 2010 with no indication of a decrease in recent years. Note that this latter study did not include any 'technology creep' factor indicating an increase in technology efficiency (which averages 2 to $3 \%$ annually; Pauly \& Palomares 2010, Stergiou \& Tsikliras 2011). Overall, we conclude that our results are consistent with the study of fishing effort (Anticamara et al. 2011), which reports the decline in biomass that can be expected given the described increase in global fishing capacity. The increase in fishing capacity has been updated and confirmed recently by additional studies (Watson et al. 2013).

It is interesting to highlight that the FAO areas were an important term in the regression model to explain the dependent variables. This importance may be related to differences in historical pressure and the expansion of fisheries in marine ecosystems (Coll et al. 2008b, Swartz et al. 2010), and it is in line with other studies suggesting that the historical evolution of fishing is a key factor to understand the dynamics seen in ecological indicators (Shannon et al. 2014, this Theme Section). The predictive variables we used in this study are not the only important factors for fish biomass, even if $70 \%$ of the variation can be explained based solely on them. There are other important variables, for instance 'rugosity' (i.e. depth variability within spatial cells), substrate types, and fishing effort, but we did not have access to global data layers covering such variables (or they were not of sufficient quality to be included), and therefore they were omitted from the analysis for the time being. In addition, the spatial distributions used within Ecospace were inferred from depths at which species are known to occur; other information such as habitat type was not included. This represents a limitation to our analysis that must be acknowledged. The implication is not that the present study is likely to be misleading, but rather that we would have obtained better predictions if we could have had added additional suitable predictor variables. In addition, although the number of ecosystem models fitted to the time series of data with Ecosim has grown substantially (Christensen \& Walters 2011, Christensen 2013), these models were not used because they do not cover the ocean in a representative way, since such models are only available for data-rich areas. However, as more fitted-to-timeseries models become available, future worldwide analysis will become possible.

It is also important to highlight that, even though spatial autocorrelation of the data was avoided due to the data sampling procedure, our cells do not provide true degrees of freedom. In addition, the $t$-values of the regressions give an indication of the internal 'ranking' of the parameters (i.e. which ones matter most). However, due to covariation between variables it must be acknowledged that the interpretation of these $t$-values needs to be treated with caution, even though the results indicated that the regression was fairly robust.

Our results also highlight that the biomass of smaller fish at lower trophic level positions has likely increased. Because our study used a trophodynamic approach, this increase is likely linked to predation release, i.e. the mechanism whereby reduction in predator populations leads to an increase in prey abundance, as documented in local and regional studies (Carscadden et al. 2001, Frank et al. 2005, Ward \& Myers 2005, Daskalov et al. 2007, Myers et al. 2007, Coll et al. 2008c, Baum \& Worm 2009), and which can be captured using trophic models. This increase in forage fish biomass is also in line with a growing importance of this resource in global fishing activities (Pikitch et al. 2012), which warns of the degradation of marine ecosystems due to the fact that these organisms are key elements of the food web (Cury et al. 2011). Further development of this study should focus on spatially describing the global distribution of smaller fish.

Overall, our findings contribute to the discussion of whether 'fishing down the food web' is a sampling artifact or something that occurs in reality (Pauly et al. 1998, Branch et al. 2010). Here, we estimated that predatory fish have declined by two-thirds, while prey fish have increased. Combined, the decrease of high trophic level fish and increase of low trophic level fish show that the trophic structure of marine ecosystems has been changed at a global scale in a manner consistent with fishing down marine food webs, in addition to that which is occurring on local 
and regional scales (Stergiou \& Christensen 2011, and see www.fishingdown.org). To add to the discussion, it should be noted that our methodology is less dependent on fisheries catch estimates than previous studies-an issue that has been central to this debate. This study is based on food web modeling results, which deliver important information regarding the 'fishing down the food web' debate (Shannon et al. 2014).

Our results have clear implications regarding changes in marine ecosystem functioning, and thus management of marine resources, since the structure of marine ecosystems may have shifted from ecosystems with larger abundance of high trophic levels and large body sizes to ecosystems dominated by lower trophic level and small body size organisms. A growing importance of forage fish in marine ecosystems due to a decrease of top-down control is of concern, since these organisms are short-lived and are much more vulnerable to environmental fluctuations (Planque et al. 2010).

Acknowledgements. This is a contribution from Sea Around Us, a scientific cooperation between the University of British Columbia (UBC) and the Pew Charitable trust. V.C. acknowledges support from the Natural Sciences and Engineering Research Council of Canada. M.C. was partially funded by the EC Marie Curie Career Integration Grant Fellowships to the BIOWEB project and the Spanish National Program Ramon y Cajal.

\section{LITERATURE CITED}

Alder J, Campbell B, Karpouzi V, Kaschner K, Pauly D (2008) Forage fish: from ecosystems to markets. Annu Rev Environ Resour 33:153-166

Anticamara JA, Watson R, Gelchu A, Pauly D (2011) Global fishing effort (1950-2010): trends, gaps, and implications. Fish Res 107:131-136

Baum JK, Worm B (2009) Cascading top-down effects of changing oceanic predator abundances. J Anim Ecol 78: 699-714

Baum JL, Myers RA, Kehler DG, Worm B, Harley SJ, Doherty PA (2003) Collapse and conservation of shark populations in the Northwest Atlantic. Science 299: 389-392

Bogorov VG, Vinogradov MD, Varonina NM, Kanaeva IP, Suetova IA (1968) Distribution of zooplankton biomass within the surficial layer of the world ocean. Dokl Akad Nauk SSSR 182:1205-1207 (in Russian)

Branch TA, Watson R, Fulton EA, Jennings S and others (2010) The trophic fingerprint of marine fisheries. Nature 468:431-435

Carscadden JE, Frank KT, Leggett WC (2001) Ecosystem changes and the effects on capelin (Mallotus villosus), a major forage species. Can J Fish Aquat Sci 23:191-219

Christensen V (2013) Ecological networks in fisheries: Predicting the future? Fisheries 38:76-81
Christensen V, Pauly D (1992) ECOPATH II — a software for balancing steady-state ecosystem models and calculating network characteristics. Ecol Model 61:169-185

Christensen V, Walters C (2004) Ecopath with Ecosim: methods, capabilities and limitations. Ecol Model 172: 109-139

Christensen V, Walters CJ (2011) Progress in the use of ecosystem models for fisheries management. In: Christensen V, Maclean J (eds) Ecosystem approaches to fisheries: a global perspective. Cambridge University Press, Cambridge

Christensen V, Garces LR, Silvestre GT, Pauly D (2003a) Fisheries impact on the South China Sea large marine ecosystem: a preliminary analysis using spatially-explicit methodology. In: Silvestre GT, Garces LR, Stobutzki I, Ahmed $M$ and others (eds) Assessment, management and future directions for coastal fisheries in Asian countries. Proc WorldFish Cent Conf 67:51-62

Christensen V, Guenette S, Heymans JJ, Walters C, Watson R, Zeller D, Pauly D (2003b) Hundred-year decline of North Atlantic predatory fishes. Fish Fish 4:1-24

Christensen V, Amorim PA, Diallo I, Diouf T and others (2004) Trends in fish biomass off Northwest Africa, 1960-2000. In: Chavance P, Ba M, Cascuel D, Vakily M, Pauly D. Marine fisheries, ecosystems, and societies in West Africa: half a century of change. IRD, Paris, p 377-386

Christensen V, Lai S, Palomares ML, Zeller D, Pauly D (eds) (2011) The state of biodiversity and fisheries in regional seas. Fish Centre Res Rep 19(3):1-61

Coll M, Bundy A, Shannon LJ (2008a) Ecosystem modelling using the Ecopath with Ecosim approach. In: Megrey B, Moksness E (eds) Computers in fisheries research, 2nd edn. Springer, Berlin, p 225-291

Coll M, Libralato S, Tudela S, Palomera I, Pranovi F (2008b) Ecosystem overfishing in the ocean. PLoS ONE 3:e3881

$>$ Coll M, Palomera I, Tudela S, Dowd M (2008c) Food-web dynamics in the South Catalan Sea ecosystem (NW Mediterranean) for 1978-2003. Ecol Model 217:95-116

> Coll M, Navarro J, Olson R, Christensen V (2013) Assessing the trophic position and ecological role of squids in marine ecosystems by means of food-web models. Deep-Sea Res II 95:21-36

Colléter M, Valls A, Guitton J, Morissette L and others (2013) EcoBase: a repository solution to gather and communicate information from EwE models. Fish Centre Res Rep 21(1):1-60

> Cury PM, Boyd IL, Bonhommeau S, Anker-Nilssen T and others (2011) Global seabird response to forage fish depletion-one-third for the birds. Science 334:1703-1706

- Daskalov GM, Grishin AN, Rodionov S, Mihneva V (2007) Trophic cascades triggered by overfishing reveal possible mechanisms of ecosystem regime shifts. Proc Natl Acad Sci USA 104:10518-10523

FAO (1981) Atlas of the living resources of the seas. FAO Fisheries Series 15, Food and Agriculture Organization of the United Nations, Rome

Ferretti F, Worm B, Britten G, Heithaus M, Lotze H (2010) Patterns and ecosystem consequences of shark declines in the ocean. Ecol Lett 13:1055-1071

> Frank KT, Petrie B, Choi JS, Leggett WC (2005) Trophic cascades in a formerly cod-dominated ecosystem. Science 308:1621-1623

Froese R, Pauly D (eds) (2013) FishBase. www.fishbase.org (accessed February 2013) 
Gjøsaeter J, Kawaguchi K (1980) A review of the world resources of mesopelagic fish. FAO Fish Tech Pap No. 193. Food and Agriculture Organization of the United Nations, Rome

Guisan A, Zimmermann NE (2000) Predictive habitat distribution models in ecology. Ecol Model 135:186

> Heymans JJ, Coll M, Libralato S, Morissette L, Christensen $\mathrm{V}$ (2014) Global patterns in ecological indicators of marine food webs: a modelling approach. PLoS ONE 9: e95845

Hilborn R, Walters C (1992) Quantitative fisheries stock assessment: choice, dynamics and uncertainty. Chapman \& Hall, New York, NY

Kaschner K, Ready JS, Agbayani E, Rius J and others (2013) AquaMaps: predicted range maps for aquatic species, version 2013. www.aquamaps.org

Lam V, Pauly D (2005) Mapping the global biomass of mesopelagic fishes. The Sea Around Us Project Newsletter 30:4

Legendre P (1993) Spatial autocorrelation: trouble or new paradigm? Ecology 74:1659-1673

> Libralato S, Coll M, Tudela S, Palomera I, Pranovi F (2008) Novel index for quantification of ecosystem effects of fishing as removal of secondary production. Mar Ecol Prog Ser 355:107-129

Lotze HK, Coll M, Magera MA, Ward-Paige C, Airoldi L (2011) Recovery of marine animal populations and ecosystems. Trends Ecol Evol 26:595-605

Myers RA, Worm B (2003) Rapid worldwide depletion of predatory fish communities. Nature 423:280-283

Myers RA, Baum JK, Shepherd TD, Powers SP, Peterson CH (2007) Cascading effects of the loss of apex predatory sharks from a coastal ocean. Science 315:1846-1850

Palomares MLD, Pauly D (eds) (2013) SeaLifeBase. www. sealifebase.org

Pauly D, Palomares MLD (2010) An empirical equation to predict annual increases in fishing efficiency. Fisheries Centre Working Paper No. 7, University of British Columbia, Vancouver

Pauly D, Christensen V, Dalsgaard J, Froese R, Torres F (1998) Fishing down marine food webs. Science 279: 860-863

Pauly D, Graham W, Libralato S, Morissette L, Palomares MLD (2009) Jellyfish in ecosystems, online databases, and ecosystem models. Hydrobiologia 616:67-85

Pikitch E, Boersma PD, Boyd IL, Conover DO and others (2012) Little fish, big impact: managing a crucial link in ocean food webs. Lenfest Ocean Program, Washington, DC

Pikitch EK, Rountos KJ, Essington TE, Santora C and others (2013) The global contribution of forage fish to marine

Submitted: March 27, 2014; Accepted: July 13, 2014 fisheries and ecosystems. Fish Fish 15:43-64

Plagányi É (2007) Models for an ecosystem approach to fisheries, Vol 477. Food and Agriculture Organization of the United Nations, Rome

$>$ Planque B, Fromentin JM, Cury P, Drinkwater KF, Jennings S, Perry RI, Kifani S (2010) How does fishing alter marine populations and ecosystems sensitivity to climate? J Mar Syst 79:403-417

Shannon JL, Coll M, Bundy A, Shin YJ and others (2014) Trophic level-based indicators to track fishing impacts across marine ecosystems. Mar Ecol Prog Ser 512: $115-140$

> Sibert J, Hampton J, Kleiber P, Maunder M (2006) Biomass, size, and trophic status of top predators in the Pacific Ocean. Science 314:1773-1776

Stergiou KI, Christensen V (2011) Fishing down food webs. In: Christensen V, Maclean J (eds) Ecosystem approaches to fisheries: a global perspective. Cambridge University Press, Cambridge, p 72-88

Stergiou KI, Tsikliras AC (2011) Fishing down, fishing through and fishing up: fundamental process versus technical details. Mar Ecol Prog Ser 441:295-301

Swartz W, Sala E, Tracey S, Watson R, Pauly D (2010) The spatial expansion and ecological footprint of fisheries (1950 to present). PLoS ONE 5:e15143

Valinassab T, Pierce G, Johannesson K (2007) Lantern fish (Benthosema pterotum) resources as a target for commercial exploitation in the Oman Sea. J Appl Ichthyology 23: 573-577

> Walters C, Pauly D, Christensen V (1999) Ecospace: prediction of mesoscale spatial patterns in trophic relationships of exploited ecosystems, with emphasis on the impacts of marine protected areas. Ecosystems 2:539-554

Walters CJ, Christensen V, Martell SJ, Kitchell JF (2005) Possible ecosystem impacts of applying MSY policies from single-species assessment. ICES J Mar Sci 62: $558-568$

> Ward P, Myers RA (2005) Shifts in open-ocean fish communities coinciding with the commencement of commercial fishing. Ecology 86:835-847

Watson RA, Cheung WWL, Anticamara JA, Sumaila RU, Zeller D, Pauly D (2013) Global marine yield halved as fishing intensity redoubles. Fish Fish 14:493-503

Worm B, Myers RA (2003) Meta-analysis of cod-shrimp interactions reveals top-down control in oceanic food webs. Ecology 84:162-173

Worm B, Barbier EB, Beaumont N, Duffy JE and others (2006) Impacts of biodiversity loss on ocean ecosystem services. Science 314:787-790

Worm B, Hilborn R, Baum JK, Branch TA and others (2009) Rebuilding global fisheries. Science 325:578-585

Proofs received from author(s): September 3, 2014 